\title{
How Stressed are our Postgraduate Medical and Dental Postgraduate Students in Southern Asia? A Cross-Sectional Survey
}

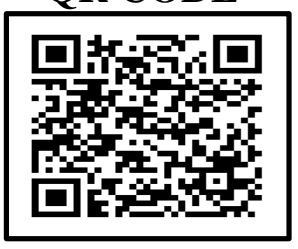

ARAVIND S. TAMILSELVAN¹, RIYA THAPA*2, ANURAG DUTT SHARMA33, TIKA THAPA², SHAILESH SINGH ${ }^{4}$

INTRODUCTION: Stress has been quite commonly reported in the literature among medical and dental students due to the nature of their work.

AIM: To assess the level of stress among medical and dental postgraduates in various medical and dental Colleges in Southern Asia.

MATERIALS AND METHOD: The study was cross-sectional in nature and conducted among 809 medical and dental postgraduates. Stress was measured using the Cohen's Perceived stress scale-14 (PSS-14) online through google forms (convenience sampling). Data was entered in MS Excel and descriptive statistics was applied followed by the independent samples t-test, post-hoc modified Bonferroni test and Odd's Ratio (OR) using SPPS version 22.0.8 Statistical significance was set at $5 \%(\mathrm{p}<0.05)$.

RESULTS: There were $342(41.3 \%)$ medical and $467(58.7 \%)$ dental postgraduates. Most medical postgraduates $(73 \%)$ reported stress as "severe", while among dental postgraduates, most of them(32.5\%) reported having "mild" stress $(\mathrm{p}=0.03)$. Among both medical and dental postgraduates, the third year of their postgraduation was found to be most stressful and the association was found to be significant ( $\mathrm{p}=0.04$ * OR:1.5). Unmarried postgraduates among both groups reported having most stress and the association was non-significant (OR: 1.1). CONCLUSION: Both medical and dental postgraduates are requested to practice stress relieving exercises and ask for help if the need arises so.

KEYWORDS: Stress, Survey, Medicine, Dentistry, Students

\section{INTRODUCTION}

Stress, a result of external physical and/or mental factors affects an individual's physical and psychological well-being and has been quite extensively reported in the literature among medical and dental students. ${ }^{1,2}$ Examples of stresses associated among such students include time management, the technical as well as technique-sensitive/intensive nature of work, clinical (both pre-clinical and clinical), submitting time bound assignments and managing uncooperative patients.

Post graduate students who decide to pursue a certain speciality are further burdened with thesis/research work, seminars and journal club presentations apart from honing their clinical skills. Handling so many things (multi-tasking) at once can result in stress, which can further lead to depression, anxiety, substance misuse, absenteeism, diminished work efficiency, and burnout. ${ }^{-5}$ Various authors have reported a high levels of stress among medical students which ranges from $27 \%$ to $73 \%{ }^{6}$

Such stresses among students exhibit a directly proportional relationship between their year of study. With promotion into every year, the burden of work increases, and the shift from pre-clinical to clinical postings is a huge transformation for the students. Hence, the present study was undertaken with the aim to assess the level of stress among medical and dental postgraduates in various medical and dental colleges in in Southern Asia.

\section{MATERIALS AND METHODS}

The present study adopted a cross-sectional study design and was conducted from $1^{\text {st }}$ October, 2019 to $31^{\text {st }}$ January, 2020. As per the initial protocol, the study was to be conducted for a year, but due to the COVID-19 pandemic, data collection had to be stopped in between and the data collected as per the specified time above was taken into consideration. As per the study design, obtaining an ethical clearance was not necessary.

Stress among the postgraduates was measured using the Cohen's Perceived stress scale-14 (PSS-14) ${ }^{7}$ and as per the study design, data was collected through convenience sampling. The questionnaire was distributed online through google forms and the link was distributed on various social media. They were informed that participation in the study was purely 
voluntary and the confidentiality of their data was assured; and to ensure this, no personal data [name, email id and phone number(s)] were collected.

PSS-14 Scoring: The questionnaire comprises of 14 questions with responses varying from zero (o) to four (4) for each item and ranging from zero $(0)=$ never, one $(1)=$ almost never, two $(2)=$ sometimes, three $(3)=$ fairly often and four (4) = very often (five-point likert scale) respectively on the basis of their occurrence during one month prior to the survey.

The scoring was calculated by obtaining the scores on four positive items and has a possible range of scores from o to 56.3. On the basis of the scores, stress was divided into the following categories: no stress $(<14)$, mild stress (15-28), moderate stress (29-42) and severe stress (43-56). For further comparisons no stress was considered as stress absent and sum of mild, moderate and severe stress were considered as stress present.

Statistical analysis: Data was entered in MS Excel and descriptive statistics was applied followed by the independent samples t-test, post-hoc modified Bonferroni test and Odd's Ratio (OR) using SPPS version 22.0. ${ }^{8} \quad$ Statistical significance was set at $5 \%$ $(\mathrm{p}<0.05)$.

\section{RESULTS}

Demographic profile of the study subjects (Table 1) The total number of respondents were 809 (100\%), of which there were 342 (41.3\%) medical and $467(58.7 \%)$ dental postgraduates. More males (58.7\%) were observed among medical postgraduates while an almost equal percentage of male $(50.5 \%)$ and female(49.5\%) dental postgraduates were observed. Most postgraduates belonged to the third year of postgraduation (medical: 54.1\%, dental:55.6\%) and were unmarried (medical: $73.2 \%$, dental:86.5\%) in both the groups (table 1 ).

\begin{tabular}{l|c|c|}
\multicolumn{1}{|c}{} & \multicolumn{1}{c}{$\begin{array}{c}\text { Medical PG } \\
\text { Students }\end{array}$} & $\begin{array}{c}\text { Dental PG } \\
\text { Students }\end{array}$ \\
\hline Gender & & \\
-M & $201(58.7 \%)$ & $236(50.5 \%)$ \\
-F & $141(41.3 \%)$ & $231(49.5 \%)$ \\
Total & $342(41.3 \%)$ & $467(58.7 \%)$ \\
\hline Year of PG & & \\
-Ist & $85(24.8 \%)$ & $111(23.7 \%)$ \\
-IInd & $72(21.1 \%)$ & $97(20.7 \%)$ \\
-IIIrd & $185(54.1 \%)$ & $259(55.6 \%)$ \\
\hline Marital Status & & \\
-Married & $95(27.7 \%)$ & $63(13.5 \%)$ \\
-Unmarried & $247(72.3 \%)$ & $404(86.5 \%)$ \\
\hline
\end{tabular}

Table 1. Demographic Profile of The Study Subjects
Stress levels among medical and dental postgraduates as per PSS-14 scoring (Table 2)

It was observed that most medical postgraduates (73\%) reported stress as "severe", while among dental postgraduates, most of them(32.5\%) reported having "mild" stress. A significant association between reported stress was found between both groups $(\mathrm{p}=0.03$, table 2$)$.

\begin{tabular}{|c|c|c|c|} 
Scores & $\begin{array}{c}\text { Medical } \\
\text { PG } \\
\text { Students }\end{array}$ & $\begin{array}{c}\text { Dental PG } \\
\text { Students }\end{array}$ & value \\
\hline No Stress $(<14)$ & $27(7 \cdot 9 \%)$ & $62(13.3 \%)$ & \\
Mild $(15-28)$ & $123(35 \cdot 9 \%)$ & $152(32.5 \%)$ & 0.03 \\
Moderate $(29-42)$ & $100(29.2 \%)$ & $119(25.9 \%)$ & \\
Severe $(43-56)$ & $92(73 \%)$ & $134(28.3 \%)$ & \\
\hline
\end{tabular}

Table 2. Stress Levels among Medical and Dental Postgraduates as per PSS-14 Scoring

\section{Detailed distribution of stress among medical and dental postgraduates (Table 3 )}

In a detailed assessment of the responses, most stress was observed among medical postgraduates (58.5\%), while similar stress percentages were found between males (49.3\%) and female dental postgraduates (50.7\%) and no statistical significance was found between the two specialities (OR: 1.3). Among both medical and dental postgraduates, the third year of their postgraduation was found to be most stressful and the association was found to be significant $\left(\mathrm{p}=\mathrm{O} .04^{*}\right.$, OR:1.5). Unmarried postgraduates among both groups reported having most stress and the association was non-significant (OR: 1.1).

\section{DISCUSSION}

The results of the present study revealed that most medical postgraduates $(73 \%)$ reported stress as "severe", while among dental postgraduates, most of them (32.5\%) reported having "mild" stress. In agreement, Sharma et al., ${ }^{9}$ reported a stress prevalence of $86 \%$ among medical postgraduates, while among dental postgraduates, stress was relatively general among all the groups of the study participants (Mathew et al.). ${ }^{10}$

In contrast, among medical postgraduates, varying prevalence of stress was found by Shete et al., (52\%), ${ }^{11}$ Malviya et al., $(58.6 \%)^{12}$ and Yusoff et al. (36.4\%). ${ }^{13}$ Among dental postgraduates, Shetty et al. found moderate to high levels of stress faced by post graduate students in their three years of training. ${ }^{14}$ 


\begin{tabular}{|c|c|c|c|c|c|c|}
\hline & \multicolumn{2}{|c|}{ Medical PG Students } & \multicolumn{2}{|c|}{ Dental PG Students } & \multirow[t]{2}{*}{ P value } & \multirow[t]{2}{*}{ OR } \\
\hline & $\begin{array}{c}\text { Stress } \\
\text { present }\end{array}$ & No Stress & $\begin{array}{c}\text { Stress } \\
\text { present }\end{array}$ & No Stress & & \\
\hline $\begin{array}{l}\text { Gender } \\
\text { M } \\
\text { F } \\
\text { Total }\end{array}$ & $\begin{array}{c}184(58.5 \%) \\
131(41.5 \%) \\
315(100 \%)\end{array}$ & $\begin{array}{l}17(62.9 \%) \\
10(37.1 \%) \\
27(100 \%)\end{array}$ & $\begin{array}{c}199(49.3 \%) \\
204(50.7 \%) \\
403(100 \%)\end{array}$ & $\begin{array}{l}37(57.8 \%) \\
27(42.2 \%) \\
64(100 \%)\end{array}$ & NS & 1.3 \\
\hline $\begin{array}{r}\text { Year of PG } \\
\text { Ist }^{\text {IInd }} \\
\text { III }^{\text {rd }} \\
\end{array}$ & $\begin{array}{c}84(26.6 \%) \\
76(24.2 \%) \\
155(49.2 \%)\end{array}$ & $\begin{array}{c}3(11.2 \%) \\
9(33 \cdot 3 \%) \\
15(55 \cdot 5 \%)\end{array}$ & $\begin{array}{c}146(36.2 \%) \\
101(25.1 \%) \\
156(38.7 \%)\end{array}$ & $\begin{array}{l}21(32.8 \%) \\
19(29.7 \%) \\
24(37.5 \%)\end{array}$ & $0.04^{*}$ & 1.5 \\
\hline $\begin{array}{c}\text { Marital Status } \\
\text { Married } \\
\text { Unmarried }\end{array}$ & $\begin{array}{c}74(23.4 \%) \\
241(76.5 \%)\end{array}$ & $\begin{array}{l}21(77 \cdot 7 \%) \\
6(22.3 \%)\end{array}$ & $\begin{array}{c}49(12.2 \%) \\
354(87.8 \%)\end{array}$ & $\begin{array}{l}21(32.8 \%) \\
43(67.2 \%)\end{array}$ & NS & 1.1 \\
\hline
\end{tabular}

Table 3. Detailed Distribution of Stress Among Medical and Dental Postgraduates (NS: Non-Significant)

It was observed that male medical postgraduates (58.5\%), reported most stress, while among dental postgraduates, female dental postgraduates (50.7\%) reported a marginally greater stress. This is lower in comparison to Chandan et al. (93.75\% stress among males $)^{15}$, and in partial agreement to Malviya et al., (45.8\% in males) among medical postgraduates. ${ }^{12}$

Among dental postgraduates, our findings were supported by Chacko et al. ${ }^{16}$ who reported that a majority of the PGs in the speciality of Orthodontics and dentofacial Orthopedics were definitely stressed, with females being more stressed than males, though the difference between two genders were nonsignificant.

In the present study, unmarried postgraduates showed lesser stress in comparison to their married counterparts and these findings are in disagreement to Chandan et al., ${ }^{15}$ who reported $100 \%$ stress among married medical postgraduates as well as Manpreet et al. ${ }^{17}$ We hypothesize that married people cope up with stress better as compared to their unmarried counterparts due to the increased ability to adapt to stress (due to increased responsibilities) after marriage.

This study is prone to limitations. The first being social desirability bias and second being the under/over reporting of data by the respondents, and to minimize its occurrence, no personal data was collected from the postgraduates. We safely state that the results of the present study can be generalized for postgraduates in South Asia and recommend that the workload of these postgraduates be reduced without affecting their learning by the institute.

\section{CONCLUSION}

The present study reported a high level of stress among medical postgraduates and apart from institute led initiatives to reduce stress, both medical and dental postgraduates are requested to practice stress relieving exercises and ask for help if the need arises so.

\section{REFERENCES}

1. Basudan S, Binanzan N, Alhassan A. Depression, anxiety and stress in dental students. Int J Med Educ. 2017; 8: 179-186. https://doi.org/10.5116/ijme.5910.b961 2. Shaik PS, Pachava S, Palli CB. Factors affecting stress among students in dental colleges of neo-capital state in India. J Indian Assoc Public Health Dent 2019;17:417. https://doi.org/10.4103/jiaphd.jiaphd_72_18

3. Tangade PS, Mathur A, Gupta R, Chaudhary S. Assessment of stress level among dental school students: An Indian outlook. Dent Res J (Isfahan) 2011;8:95-101.

4. Shaikh BT, Kahloon A, Kazmi M, Khalid H, Nawaz K, Khan N, et al. Students, stress and coping strategies: A case of Pakistani medical school. Educ Health (Abingdon). 2004;17:346-53.

5. Saipanish R. Stress among medical students in a thai medical school. Med Teach. 2003;25:502-6.

6. Solanky P, Desai B, Kavishwar A, Kantharia SL. Study of psychological stress among undergraduate medical students of Government Medical College, Surat. Int J Med Sci. Public Health 2012;1:38-42.

7. Cohen S, Kamarck T, Mermelstein R. A global measure of perceived stress. Journal of Health and Social Behavior 1983;24:385-96.

8. IBM Corp. Released 2013. IBM SPSS Statistics for Windows, Version 22.0. Armonk, NY: IBM Corp. 
9. Sharma B, Prasad S, Pandey R, Singh J, Sodhi KS, Wadhwa D. Evaluation of Stress among Post-graduate Medical and Dental Students: A pilot study. Delhi Psychiatry Journal 2013;16(2):312-6.

10. Mathew MJ, Sudeep C B, Jain J, Jain V. Perceived sources of stress among postgraduate students of a dental college in Karnataka, India. J Indian Assoc Public Health Dent 2017;15:230-3. https://doi.org/10.4103/jiaphd.jiaphd_38_17

11. Shete AN, Garkal KD. A study of stress, anxiety and depression among postgraduate medical students. Chrismed J Health Res. 2015;2:119-23.

12. Malviya A, Tiwari S, Meena V, Binti S, Singh D. Stress Among Post Graduate Medical Students in Central India: A Cross Section Study Using Perceived Stress Scale. GJRA 2016;5(3):368-70.
13. Yusoff MSB, Rahim AFA. Prevalence and Sources of Stress among Postgraduate Medical Trainees: Initial Findings. ASEAN Journal of Psychiatry 2010;11(2):1-10.

14. Shetty A, Shetty A, Hegde MN, Narasimhan D, Shetty S. Stress and Burnout Assessment Among Post Graduate Dental Students. Nitte University Journal of Health Science (NUJHS) 2015; 5(1):31-6.

15. Chandan N, Sherkhane MS. Assessment of Stress and Burnout among Postgraduate Medical Students. Natl J Community Med. 2017; 8(4):178-82.

16. Chacko A, Tikku T, Srivastava K. Evaluation of psychological stress in orthodontic PG students in India. Int J Orthod Rehabil. 2017;8:19-25. https://doi.org/10.4103/2349-5243.200218

17. Manpreet K, Maheshwari SK. Depression, Anxiety and Stress among Postgraduate Nursing Students. Int J Therap Appl. 2015;21:12-8. 